\title{
Assessment of Employees' Involvement Influence on Performance of MTNOs in Kenya
}

\author{
Grace Karemu, Musa Nyakora, Erastus M. Thoronjo, and Evans Nyamboga Mandere
}

\section{ABSTRACT}

\begin{abstract}
The researcher aimed to assess the extent of employees' involvement on performance of Mobile Telephone Network Operators in Kenya. Employees' involvement was measured in terms of employees' autonomy, quality circles and employees' suggestion schemes. Performance was assessed using profit margins and market share. Both quantitative and qualitative methods were used while gathering and analyzing primary data. The study requested respondents to fill five-point Likert scale questionnaires during collection of primary while published information was obtained from the MTNOs end of year reports. Total population for research was comprised of all full-time employees in Safaricom, Airtel and Telkom Mobile Telephone Network Operators which was 6,167. Given out to respondents were 361 questionnaires but 258 were received back. SPSS was used to obtain descriptive statistics, to do factor analysis, correlation analysis and regression analysis. Data was analyzed at $95 \%$ confidence interval and $0.05 \alpha$. The tested $\mathrm{H}_{0}$ stated that: The relationship between employees' involvement and performance of Mobile Telephone Network Operators in Kenya is not statistically significant. However, regression analysis model gave $R=0.695 ; R^{2}=0.483 ; \beta=0.695$ and $\mathbf{P}=\mathbf{0 . 0 0 0}$ meaning that employees' involvement had a positive relationship with performance of MTNOs since it was responsible for $48.3 \%$ of variation in performance. The null hypothesis $\left(\mathrm{H}_{0}\right)$ was rejected, and the researcher stated that the relationship between employees' involvement and performance was statistically significant and positive.
\end{abstract}

Keywords: Employees' Involvement, organization's performance.
Submitted : September 01, 2021

Published : September 24, 2021

ISSN: $2507-1076$

DOI: $10.24018 / \mathrm{ejbmr} .2021 .6 .5 .1085$

Grace Karemu*

Mount Kenya University, Kenya.

(E-mail: gracekaremu2000@gmail.com) Musa Nyakora

Adventist University of Africa, Kenya.

(E-mail: nyakora.musa@yahoo.com)

Erastus M. Thoronjo

Mount Kenya University, Kenya.

(E-mail: ethoronjo@mku.ac.ke)

Evans Nyamboga Mandere

Mount Kenya University, Kenya.

(E-mail: enyamboga ${ }^{@}$ mu.ac.ke)

* Corresponding Author

\section{BACKGROUND TO THE STUDY}

High performing companies introduce employees' involvement which leads to high employee engagement and subsequently results to higher performance according to [1]. Employees' involvement in decisions affects their morale positively creating belongingness to the company and this enables employees to accept and own any organizational change because they are committed to organizational goals as a result of involvement. Employee involvement gets them attached to the firm and understanding this, management is able to infuse ownership feelings among all employees by giving them a stake in decision making and valuing their suggestions without partiality [2]. Employees' involvement whether empowerment is through autonomy, quality circles or employee suggestion schemes gives them better understanding of their job roles and positive attitudes toward the company and the company's goals and objectives, which develops due to enhanced ability to participate in decision making [2]. Involvement increases employees' awareness and knowledge of the organization and helps them gain understanding of how to best carry out job roles while connecting with set broad goals in the company [3]. Specifically, involvement makes employees to gain meaning of their work, getting more understanding of their job roles, and personally contributing to better performance of the enterprise. This leads to development of personal accountability, responsibility and eventually ownership over personal job roles and the set organizational goals, objectives, and targets. Reference [4] shows that involving employees in decision making gets them engaged with organizational activities since they gain understanding of the contributions which they directly make towards the performance of the company. Reference [2] also underscored that organizations which makes employees to have feelings of ownership through involvement usually perform better than other companies in the same industry.

\section{A. Statement of the Problem}

Companies' end of year reports for all the three MTNOs in the last seven years and above indicate several performance challenges encountered by the MTNOs: Safaricom's mobile money market share in 2014 dropped by $3.1 \%$ to $75.6 \%$ from $78.7 \%$, whereas its subscribers' market share dropped to $66.3 \%$ a $1.7 \%$ decline from $67.0 \%$. In March 2016, Safaricom reported a decline in SMSs by $19.3 \%$ to 5.8 billion messages down from 7.3 billion whereas in December 2015 the MTNO dropped to attain a SMS market share of $89.9 \%$ down from 90.7\% (Communications Authority of Kenya (CAK), 2016). Also, in June 2017 Safaricom Ltd registered local voice traffic of 8.4 billion minutes down from 8.5 billion, hence having a drop in voice market from $82 \%$ to $79.6 \%$ (CAK report, 2017). In July-September 2018 total mobile voice traffic from Safaricom network dropped by 2.4 per cent to 
record 8.9 billion minutes from 9.1 billion minutes reported during the previous quarter, and its voice market share dropped to 62.1 per cent from 65.7 per cent reported in the previous quarter (CAK sector statistics report of 2017/2018).

Performance of Airtel Kenya Ltd has been ridden with myriads of challenges from the time it entered Kenya in 2000. Airtel disclosed in 2016 that it was bankrupt and could not meet its financial obligations and was helpless with hundreds of employees who had to be sacked to be able to radically restructure its operations. According to industry report of $2018 / 2019$, Airtel's subscribers share of the market went down from 15.3 per cent in June 2017 to 14.9 per cent as of September 2018 and during the March-July 2017 quarter Airtel MTNO had lost 5 million mobile money subscribers and half a million data network subscribers (CAK report, December 2018). Airtel reported negative profits between the years 2010 to 2018 according to company reports: even after frequently changing management and rebranding.

Telkom in the last 10 years always faced challenges which made profitability for the MTNO a mirage, and as a result the company has always reported low performance in terms of profitability and market share relative to other MTNOs. The government divested its stake from $100 \%$ to $49 \%$, with France Orange acquiring 51\% in 2007; rebranding to Orange Telkom (CAK, 2016) but even after the acquisition the company still reported negative financial returns followed by massive employees' retrenchments. Under the management of France Orange, Telkom never made profits but instead continued to report losses. France Orange left Telkom after nine years of loss-making in Kenya selling its entire stake in the firm to Helios, a UK private equity firm and the MTNO rebranded again to Telkom Kenya in 2017. Despite several strategic changes in Telkom Kenya, the MTNO still reported losses (Communications Authority of Kenya, 2019).

\section{B. Objective of the Study}

This research purposed to assess the effect of employees' involvement on performance of Mobile Telephone Network Operators in Kenya.

\section{Research Hypothesis}

$\mathrm{H}_{0}$ : The relationship between employees' involvement and performance of Mobile Telephone Network Operators in Kenya is not statistically significant.

\section{LITERATURE REVIEW}

\section{A. Empirical Literature Review}

Many researchers have studied employees' involvement on organization's performance and published findings.

A study was carried out by [5] to evaluate how employees' involvement practices in some steel producing companies in Kenya affected financial performance. Descriptive research design was employed to gather numerical and non-numerical facts through structured research instruments. Targeted population comprised of 46 companies registered in Kenyan as steel manufacturing companies. Confirmation of hypotheses was examined using ANOVA.

The researcher concluded that employees' involvement affected the extent to which financial objectives were realized in steel making firms. Regression analysis showed that employees' involvement influenced performance, since $\mathrm{F}$ statistic was $74.809(\mathrm{P}=0.000<0.05)$. There was also a useful connection linking employees' involvement practices and performance where $\mathrm{R}=0.718, \mathrm{P}<0.05$. Reference [5] research focus was on a chosen number of steels producing companies in Kenya and not on MTNOs leaving a knowledge blank which was addressed in this research by assessing effect of employees' involvement on performance of MTNOs.

A study on impact of participation and profitability of some SMEs in Kitale, Kenya was done by [6]. Facts were obtained from 129 employees and 27 managers using questionnaires. Data generated were examined using descriptive statistics and outcome revealed involvement of employees gave a notable useful outcome on profitability. The study suggested that rising members of staff's involvement impacted more positively on the growth and ability to survive of SMEs. Reference [6] study was done on SMEs and not on MTNOs in Kenya. This research determined the effect of employees' involvement on profit margins and market share in Mobile Telephone Network Operators.

A similar study was done by [7] on effect of job involvement on organization's performance with citizenship behavior as intervening variable. Research instruments enabled gathering of facts from workers of a Japanese university. Data was interpreted using means, standard deviations, correlation, and regression analysis. Hypothesis was that affective job involvement positively influenced performance. However, after testing the hypothesis, the hypothesis was rejected since cognitive job involvement had a negative relationship with performance and organizational citizenship behaviour giving results as $\beta=-0.257$; $\mathrm{P}<0.05$.

Reference [7] concluded that employees' involvement negatively affected performance and organizational citizenship behaviour. Reference [7] however, studied a Japanese university and not MTNOs presenting a research gap which was filled by this study by assessing employees' involvement on performance of MTNOs in Kenya.

Reference [8] examined the connection between employees' involvement and output of a production industry in Nigeria. Information was gathered from employees of 670 companies and descriptive statistics were generated. The outcomes of the analysis of data indicated obtained statistics were significant meaning the association between employees' involvement and firms' performance was also significant. Recommendations from the study embraced the requirement for manufacturing firms to practice higher degrees of workers' involvement in decisions for improvement of performance. Reference [8] study was done in Nigeria and not in Kenya creating a research gap. This gap has been covered by assessing effect of employees' involvement on profit margins and market share (performance) in MTNOs

Reference [9] studied how part-time lecturers' involvement in decision making affected their performance in government sponsored universities in Kenya. Research instruments with standardized questions were given out to get opinions from the 60 participants. Data was analyzed and summarized using percentages, averages, and standard deviations. Employees' involvement had a strong and positive interaction with employee performance where 
correlation was notable at $\mathrm{r}=0.665$. Employees' involvement was responsible for $66.5 \%$ of entire output in employees' performance having a substantial contribution.

Reference [9] concluded part-time lecturers' involvement in decision making affected their performance and hence performance of universities positively. Recommendations were that Universities should find ways of involving part time lecturers in decision making to positively affect performance, growth, and competitiveness. Reference [9] study involved part time lecturers and not MTNOs'; therefore, this research addressed this gap by assessing how employees' involvement influences performance of MTNOs in Kenya.

\section{B. Conceptual Framework}

Reference [10] showed that study variables can be presented in form of a diagram. Interactions between independent and dependent variables are shown in the form of arrows. The researcher used a diagrammatic figure to demonstrate relationships between employees' involvement (employees' autonomy, quality circles and employees' suggestion schemes) and performance (profit margins and market share). This research assessed how employees' involvement influences performance of MTNOs in Kenya. The relationship between employees' involvement and performance of MTNOs was assumed to be moderated by the Ministry of communications guidelines and communications authority of Kenya regulations.

Reference [11] suggested that employees' involvement in decision making contributes toward creating feelings of ownership which allows employees to develop a strong understanding of business functioning and to have knowledge on how they can influence business performance resulting in a workforce which is loyal and interested in the company's success. Reference [12] indicated that employees' involvement contributes greatly to organization's performance. In this study the researcher chose to assess employees' involvement in MTNOs in Kenya using employees' autonomy, quality circles and employees' suggestion schemes. Performance was measured in terms of profit margins and market share

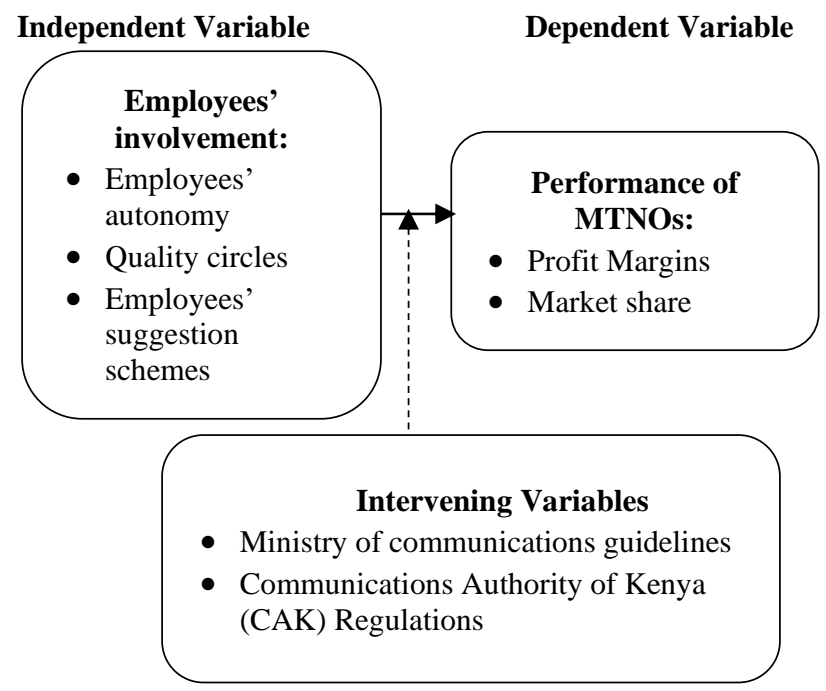

Fig. 1. Conceptual Framework. Source: Researcher, 2020.

\section{RESEARCH METHODOLOGY}

This is a technique for assembling needed data with a motive of analyzing, explaining results, making conclusions and decisions, and giving recommendations [13]. Methodology can either be qualitative or quantitative research technique of gathering information, which may contain current or historical information [14]. Quantitative methods which emphasize analysis of numerical information was applied when collecting quantitative facts with aid of structured questions while qualitative data was gathered through open ended questions. The study used mixed research methodology to collect both qualitative and quantitative data. The researcher gathered data from employees concerning employees' involvement. Statistical models were constructed to explain what was observed, and explanatory notes to explain qualitative information were written, according to [13].

\section{A. Target Population}

The total number of employees from which sample for the study was drawn comprised of all permanent members of staff in the three Mobile Telephone Network Operators; which was 6,167 as follows: Safaricom - 4,245 employees according to (Safaricom's annual report, 2017); Airtel 1,136 full time staff (company report of December 2018) and Telkom - 786 employees (company's annual report of 2018). The entire population targeted by the researcher was 6,167 as presented in Table I.

TABLE I: TARGET POPULATION

\begin{tabular}{ccccc}
\hline \multicolumn{5}{c}{ TABLE I: TARGET POPULATION } \\
\hline Department & Safaricom & Airtel & Telkom & T/P \\
\hline Finance & 94 & 33 & 23 & 150 \\
Mobile money & 262 & 76 & 53 & 391 \\
HRM & 96 & 21 & 17 & 134 \\
Procurement & 57 & 18 & 15 & 90 \\
Marketing & 316 & 134 & 94 & 544 \\
Customer care & 1282 & 423 & 287 & 1992 \\
Innovations & 93 & 46 & 36 & 175 \\
Engineering & 167 & 58 & 41 & 266 \\
Business unit & 64 & 27 & 18 & 109 \\
Strategy MGT & 253 & 32 & 23 & 308 \\
Sales MGT & 1052 & 141 & 96 & 1289 \\
Operations & 437 & 94 & 62 & 593 \\
Distribution & 72 & 33 & 21 & 126 \\
\hline Total & 4,245 & 1,136 & 786 & 6,167 \\
\hline HRM - Human Resource Management, MGT - Management and T/P-Total \\
Population. & \multicolumn{4}{|c}{} \\
Source: Safaricom Kenya, Airtel Kenya and Telkom Kenya records, (2019).
\end{tabular}

\section{B. Sampling Procedure and Sample Size}

Krejie and Morgan sample size table [15] helped the scholar to pick sample size for the study, which was 361, and therefore 361questionnaires were distributed. To avoid disproportionate distribution of questionnaires, the researcher used proportionate stratification formula [16] such that departments with high population of employees receive higher numbers of questionnaires than those with lower numbers of employees calculated as follows:

$$
n_{h}=\frac{N_{h} x n}{N}
$$

where

$\mathrm{n}_{\mathrm{h}}=$ Respondents for department, $\mathrm{h}$;

$\mathrm{N}_{\mathrm{h}}=$ the population size for department, $\mathrm{h}$; 
$\mathrm{N}=$ total population size;

$\mathrm{n}$ = Study's sample size.

Table II below shows how the 361 questionnaires were proportionately distributed to all departments of the MTNOs according to [16].

TABLE II: SAMPLE SIZE

\begin{tabular}{ccccc}
\hline Department & SF & AT & TK & Total \\
\hline Finance & 6 & 2 & 1 & 9 \\
Mobile money & 15 & 4 & 3 & 22 \\
HRM & 6 & 1 & 1 & 8 \\
Procurement & 3 & 1 & 1 & 5 \\
Marketing & 18 & 8 & 6 & 32 \\
Customer care & 75 & 25 & 17 & 117 \\
Innovations & 5 & 3 & 2 & 10 \\
Engineering & 10 & 3 & 2 & 15 \\
Business unit & 4 & 1 & 1 & 6 \\
Strategy MGT & 15 & 2 & 1 & 18 \\
Sales MGT & 62 & 8 & 6 & 76 \\
Operations & 25 & 6 & 5 & 36 \\
Distribution & 4 & 2 & 1 & 7 \\
\hline Total & 248 & 66 & 47 & 361 \\
\hline
\end{tabular}

Source: Researcher, 2019.

Key: T/P-Total Population, SS-Sample Size.

SF- Safaricom, AT-Airtel, TK- Telkom

\section{Data Analysis Techniques}

SPSS was used to: generate descriptive statistics, statistics (means and standard deviations), to do factor analysis (Kaiser Meyer Olkin and Bartlett's tests), to obtain Carl Pearson correlation relationships and to do regression analysis for hypothesis testing.

\section{DATA ANALYSIS AND FINDINGS}

\section{A. Descriptive Statistics for Employees' Involvement}

Means and standard deviations were generated for all studied employees' involvement measures (employees' autonomy, quality circles, and employees' suggestion schemes). Likert scale questionnaire statements were rated by participants and responses were used to calculate descriptive statistics as shown in Table III.

Descriptive statistics were obtained and the overall mean score of employees' involvements was (3.8744). The statement: employees' autonomy leads to an increased sense of ownership toward the MTNO enhancing productivity scored a mean of 3.8760 and the statement; job satisfaction achieved from employees' autonomy ensures ownership of MTNOs goals increasing performance had a mean score of 3.9729 .

The statement that; quality circles gives employees sense of belonging and ownership of company's goals improving performance scored 4.0349; suggestion schemes enables employees to own their work processes which improves employee morale and performance scored a mean of 3.7093; suggestion schemes increase employee job satisfaction making them to own decisions hence increases performance got a score of 3.6744; and employees' suggestion schemes build team spirit and ownership of targets improving their productivity hence performance of MTNOs got a score of 3.6047 whereas suggestion schemes give employees job satisfaction and ownership of their job roles increasing had an average of 3.5349 and the statement employees' suggestion schemes create a sense of ownership and increase employee engagement to boost performance had mean score of 3.7907 .

\begin{tabular}{|c|c|c|c|}
\hline Statements in the Questionnaire & $\mathrm{N}$ & Mean & Std. Dev. \\
\hline $\begin{array}{l}\text { Employees' autonomy is used to } \\
\text { reinforce the culture of ownership for } \\
\text { better employee efficiencies }\end{array}$ & 258 & 3.7636 & 1.1098 \\
\hline $\begin{array}{l}\text { Employees' autonomy leads to increased } \\
\text { sense of ownership toward the MTNO } \\
\text { enhancing productivity }\end{array}$ & 258 & 3.8760 & 1.0623 \\
\hline $\begin{array}{l}\text { Job satisfaction achieved from } \\
\text { employees' autonomy ensures ownership } \\
\text { of MTNOs goals increasing performance }\end{array}$ & 258 & 3.9729 & 1.0601 \\
\hline $\begin{array}{l}\text { Employees' autonomy instills } \\
\text { commitment leading to ownership of } \\
\text { organizational objectives for better } \\
\text { performance }\end{array}$ & 258 & 4.0426 & 1.0222 \\
\hline $\begin{array}{l}\text { Autonomy increases employees' sense of } \\
\text { belonging hence they embrace the } \\
\text { ownership culture to boost performance }\end{array}$ & 258 & 4.1473 & 0.95094 \\
\hline $\begin{array}{l}\text { Quality circles gives employees sense of } \\
\text { belonging and ownership of company's } \\
\text { goals improving performance }\end{array}$ & 258 & 4.0349 & 1.1065 \\
\hline $\begin{array}{l}\text { Quality circles allows employee to } \\
\text { cultivate feelings of ownership toward } \\
\text { their jobs hence perform to their best }\end{array}$ & 258 & 4.1124 & 1.0691 \\
\hline $\begin{array}{l}\text { Quality circles gives employees } \\
\text { commitment which leads to ownership of } \\
\text { job-related decisions hence better } \\
\text { performance }\end{array}$ & 258 & 3.7946 & 1.1470 \\
\hline $\begin{array}{l}\text { Decisions reached during quality circles' } \\
\text { meetings encourages ownership of } \\
\text { decisions improving performance }\end{array}$ & 258 & 3.9690 & 1.0053 \\
\hline $\begin{array}{l}\text { Quality circles give employees wide } \\
\text { knowledge to fit in their jobs gaining } \\
\text { sense of ownership hence performs better }\end{array}$ & 258 & $\begin{array}{c}4.0891 \\
0\end{array}$ & 0.94385 \\
\hline $\begin{array}{l}\text { Suggestion schemes enables employees } \\
\text { to own their work processes which } \\
\text { improves employee morale and } \\
\text { performance }\end{array}$ & 258 & 3.7093 & 1.2369 \\
\hline $\begin{array}{l}\text { Employees' suggestion schemes create a } \\
\text { sense of ownership and increase } \\
\text { employee engagement to boost } \\
\text { performance }\end{array}$ & 258 & 3.7907 & 1.1681 \\
\hline $\begin{array}{l}\text { Suggestion schemes give employees job } \\
\text { satisfaction and ownership of their job } \\
\text { roles increasing performance }\end{array}$ & 258 & 3.5349 & 1.2664 \\
\hline $\begin{array}{l}\text { Employees' suggestion schemes build } \\
\text { team spirit and ownership of targets } \\
\text { improving their productivity hence } \\
\text { performance }\end{array}$ & 258 & 3.6047 & 1.1928 \\
\hline $\begin{array}{l}\text { Suggestion schemes increase employee } \\
\text { job satisfaction making them to own } \\
\text { decisions hence increases performance }\end{array}$ & 258 & 3.6744 & 1.2794 \\
\hline
\end{tabular}

$\mathrm{N}=$ Number of respondents,

Std. Dev. $=$ Standard Deviation

Source: Primary Data, 2020

\section{Factor Analysis}

Data adequacy was tested by using Kaiser Meyer Olkin test and Bartlett's test was used check linear characteristics within the data set. Reference [17] shows that a KMO value of $>.5$ means the data set has sampling adequacy and therefore appropriate for factor analysis, and a Bartlett's test with $\mathrm{P} \leq .05$ is an indication that data is good for component analysis. Data on sub-independent variables which defined employees' involvement (employees' autonomy, quality circles, and employees' suggestion schemes) were put through KaiserMeyer-Olkin (KMO) and Bartlett's tests and results were as given in Table IV: 
TABLE IV: KMO AND BARTLETT'S TESTS

\begin{tabular}{ccc}
\hline KMO & \multicolumn{3}{c}{0.669} \\
B/T & Approx. Chi- Square & 230.619 \\
& df. & 14 \\
& Sign & 0.000 \\
\hline
\end{tabular}

Source: Primary Data, 2020.

From Table IV results, KMO of 0.699 suggests data collected for this research was appropriate for component analysis since $\mathrm{P} \leq 0.05$, with Chi- Square of 230.619 and 14 degrees of freedom. The results in Table IV indicate that the data gathered during the study met the required threshold for factor analysis. Factor extraction process was done on the data in order to establish the linear components within the data (eigenvectors), and to establish how the fifteen questionnaire items of analysis loaded into specific components. This involved subjecting data for all the three employees' involvement constructs (employees' autonomy, quality circles and employees' suggestion schemes) into factor analysis. The researcher retained components with eigenvalues $\geq 1$ according to [18]. Four components were isolated to be subjected to further detailed analysis showing variances attributable to each factor as given in Table V.

TABLE V: INITIAL EIGENVALUES AND TOTAL VARIANCES

\begin{tabular}{|c|c|c|c|c|c|c|}
\hline \multirow{2}{*}{ Items } & \multicolumn{4}{|c|}{ Initial Eigenvalues } & \multicolumn{2}{|c|}{$\begin{array}{l}\text { Sums of Squared } \\
\text { Loadings }\end{array}$} \\
\hline & Total & Variance $\%$ & $\underset{\%}{\text { Cumulative }}$ & Total & $\begin{array}{c}\% \text { of } \\
\text { Variance }\end{array}$ & $\begin{array}{c}\text { Cumulative } \\
\%\end{array}$ \\
\hline 1 & 2.993 & 25.761 & 25.761 & 2.993 & 15.761 & 15.761 \\
\hline 2 & 1.995 & 20.507 & 46.268 & 1.995 & 10.507 & 26.268 \\
\hline 3 & 1.689 & 9.947 & 56.215 & 1.689 & 8.893 & 35.161 \\
\hline 4 & 1.586 & 8.893 & 65.108 & 1.586 & 8.353 & 43.514 \\
\hline 8 & 0.992 & 5.750 & 70.859 & & & \\
\hline 9 & 0.928 & 5.411 & 76.270 & & & \\
\hline 10 & 0.913 & 5.336 & 81.606 & & & \\
\hline 11 & 0.931 & 4.903 & 86.509 & & & \\
\hline 12 & 0.793 & 4.175 & 90.684 & & & \\
\hline 13 & 0.749 & 3.944 & 94.628 & & & \\
\hline 14 & 0.574 & 3.025 & 97.653 & & & \\
\hline 15 & 0.446 & 2.347 & 100.000 & & & \\
\hline
\end{tabular}

Extraction Method: Principal Component Analysis.

Source: Primary Data, 2020.

The study found four most important factors attributable to employees' involvement accounting for $65.108 \%$ of total variation in employees' involvement constructs (Table V). Factor 1 had the most prevailing loading accounting for $25.761 \%$ of the total variation of employees' involvement constructs. Factor 2 was found to be accounting for $20.507 \%$ of total variation, factor 3 accounted for $9.947 \%$ factor 4 contributed $8.893 \%$ of total variation. The identified four components were analyzed further using rotated component matrix. The rotated component matrix results for employees' involvement indicators are in Table VI below.

Four factors were isolated for further analysis as given in Table VI above. Component one among others was loaded with the statements that; Employees' autonomy is used to reinforce the culture of ownership for better employee efficiencies (0.924); Quality circles gives employees sense of belonging and ownership of company's goals improving performance (0.804); Quality circles give employees wide knowledge to fit in their jobs gaining sense of ownership hence performs better (0.827) and Employees' suggestion schemes build team spirit and ownership of targets improving their productivity hence performance of MTNOs (0.803). The rest of the statements loaded to components 2, 3 and four as shown on Table VI.

TABLE VI: ROTATED MATRIX FOR EMPLOYEES' INVOLVEMENT COMPONENTS

Questionnaire statements

Employees' autonomy is used to reinforce the culture of ownership for better employee efficiencies. Employees' autonomy leads to increased sense of ownership toward the MTNO enhancing productivity.

Job satisfaction achieved from employees' autonomy ensures ownership of MTNOs goals increasing performance.

Employees' autonomy instills commitment leading to ownership of organizational objectives for better performance.

Autonomy increases employees sense of belonging hence they embrace the ownership culture to boost performance.

Quality circles gives employees sense of belonging and ownership of company's goals improving performance.

Quality circles allows employee to cultivate feelings of ownership toward their jobs hence perform to their best.

Quality circles give employees commitment which leads to ownership of job related decisions hence better performance.

Quality circles gives employees sense of belonging and ownership of company's goals improving performance.

Quality circles give employees wide knowledge to fit in their jobs gaining sense of ownership hence performs better.

Suggestion schemes enable employees to own their work process which improves employee morale and performance.

Employees' suggestion schemes create a sense of ownership and increase employee engagement to boost performance

Employees' suggestion schemes create a sense of ownership and increase employee engagement to boost performance

Employees' suggestion schemes build team spirit and ownership of targets improving their productivity hence performance of MTNOs

Suggestion schemes increase employee job satisfaction making them to own decisions hence

\begin{tabular}{|c|c|c|c|}
\hline 1 & 2 & 3 & 4 \\
\hline 0.924 & 0.035 & 0.088 & 0.251 \\
\hline 0.144 & 0.127 & 0.796 & 0.064 \\
\hline 0.034 & 0.830 & 0.162 & 0.095 \\
\hline 0.444 & 0.749 & 0.139 & 0.730 \\
\hline 0.055 & 0.119 & 0.837 & 0.067 \\
\hline 0.804 & 0.147 & 0.023 & 0.043 \\
\hline 0.172 & 0.300 & 0.400 & 0.781 \\
\hline 0.032 & 0.873 & 0.046 & 0.012 \\
\hline 0.102 & 0.895 & 0.072 & 0.062 \\
\hline 0.827 & 0.070 & 0.018 & 0.021 \\
\hline 0.166 & 0.061 & 0.805 & 0.120 \\
\hline 0.064 & 0.307 & 0.710 & 0.080 \\
\hline 0.064 & 0.307 & 0.410 & 0.780 \\
\hline 0.803 & 0.277 & 0.468 & 0.070 \\
\hline
\end{tabular}
performance

Extraction Method: Principal Component Analysis.

Source: Primary Data, 2020.

\section{E. Correlation Analysis}

Correlation between employees' involvement constructs and the dependent variable was ascertained utilizing Carl Pearson moment correlation. Table VIII shows correlation 
results between employees1 autonomy and performance; quality circles and performance and employees' suggestion schemes and performance. Correlations between the measures of employees' involvement are also shown in Table VII below:

\begin{tabular}{ccccc}
\multicolumn{5}{c}{ TABLE VII: EMPLOYEES' INVOLVEMENT AND PERFORMANCE } \\
\hline & $\mathrm{P}$ & EA & QC & ESS \\
\hline Organizations' Performance & 1. & & & \\
Employees' autonomy & $0.362^{*}$ & 1. & & \\
Quality Circles & $0.198^{*}$ & $0.134^{*}$ & 1. & \\
Employees' Suggestion Schemes & $0.466^{*}$ & $0.364^{*}$ & $0.342^{*}$ & 1 \\
\hline
\end{tabular}

$* 0.05$ level of significance.

Key: P - performance, EA - Employees' Autonomy, QC - Quality Circles, ESS - Employees' Suggestion Schemes.

Table VII above indicate that employees' autonomy, quality circles and employees' suggestion schemes had a positive relationship with performance of MTNOs: $(\mathrm{r}=$ $0.362, \mathrm{P}<0.05),(\mathrm{r}=0.198, \mathrm{P}<0.05)$ and $(\mathrm{r}=0.466, \mathrm{P}<$ $0.05)$. It meant that all the researched measures of employees' involvement had a positive effect on performance of MTNOs.

The results concurred with [5] who evaluated how employees' involvement practices in steel producing companies in Kenya affected financial performance and found a notable association in the constructs where $r=0.718$, $\mathrm{P}<0.05$. The results also agreed with [9], who studied how part-time lecturers' involvement in decision making affected their performance in public universities in Kenya and found employees' involvement to have a strong and positive association with their performance where $\mathrm{r}=0.665, \mathrm{P}<0.01$ : [5] and [9] concluded that employees' involvement influence firm performance positively.

\section{F. Regression Analysis}

The purpose of this research was to assess the extent of employees' involvement (Employees' autonomy, quality circles and employees' suggestion schemes) influence on performance of MTNOs in Kenya. Participants indicated how employees' involvement affected performance of their companies by responding to given statements on a Likert scale. Regression analysis was done and hypothesis for the study was tested: Results of simple regression analysis are shown on Table VIII:

TABLE VIII: EMPLOYEES' INVOLVEMENT AND PERFORMANCE

\begin{tabular}{ccccc}
\multicolumn{5}{c}{ MODEL SUMMARY } \\
\hline Model & $\mathrm{R}$ & $\mathrm{R}^{2}$ & Ad. $^{2}$ & SEE \\
\hline 1 & $0.695^{\mathrm{a}}$ & 0.483 & 0.481 & 0.93132 \\
\hline
\end{tabular}

a. Employees' Involvement (independent variable).

b. MTNOs performance (dependent variable).

Simple regression model on Table VIII gave a high and a positive relationship between employees' involvement and the dependent variable presented by $\mathrm{R}=0.695$ and $\mathrm{R}^{2}=$ 0.483 . The independent variable could therefore influence $48.3 \%$ of the changes in the dependent variable.

The ANOVA table (Table IX) indicated that the regression analysis model of employees' involvement and MTNOs performance was significant at $\mathrm{F}=50.114(1,256) \mathrm{P}<0.05$.
TABLE IX: EMPLOYEES’ INVOLVEMENT AND PERFORMANCE

\begin{tabular}{ccccccc}
\multicolumn{7}{c}{ ANOVA } \\
\hline $\mathrm{M}$ & & SS & DF & MS & F & Sig \\
\hline 1 & Reg. & 207.433 & 1 & 207.433 & 239.254 & $0.000^{\mathrm{a}}$ \\
& Res. & 222.043 & 256 & 0.867 & & \\
& Total & 429.476 & 257 & & & \\
\hline
\end{tabular}

a. Predictors: (Constant), Employees' Involvement.

b. Dependent Variable: Organizations' performance.

Key: Reg. - Regression, Res - Residual, SS - Sum of Squares, MS - Mean Square, DF- Degrees of Freedom.

\section{G. Hypothesis Testing}

The null hypothesis test was based on standardized coefficient and the $\mathrm{P}$ value: The researcher was to reject the null hypothesis if the standardized coefficient $(\beta)$ was not equal to zero and the $\mathrm{P}$ value was greater than 0.05 ; otherwise, the researcher was to accept the null hypothesis. This test was based on the fact that the null hypothesis for simple linear regression is $\beta \neq 0$ and if the obtained standardized coefficient ( $\beta$ ) is equal to zero, then the null hypothesis is retained. Table $\mathrm{X}$ shows simple regression analysis model that was used for hypothesis testing: the model gave unstandardized coefficients (UC), standardized coefficients (SC) and the level of significance. Since the beta $(\beta)$ is 0.695 and not zero $(\beta \neq 0)$ the researcher rejected the null hypothesis.

TABLE X: EI AND PERFORMANCE OF MTNOS SIMPLE REGRESSION COEFFICIENTS MODEL

\begin{tabular}{|c|c|c|c|c|c|c|}
\hline \multirow{2}{*}{ M } & & \multicolumn{2}{|c|}{$\mathrm{UC}$} & \multicolumn{2}{|c|}{$\mathrm{SC}$} & \multirow[b]{2}{*}{ Sig } \\
\hline & & B & Std. Error & $\operatorname{Beta}(\beta)$ & $\mathrm{T}$ & \\
\hline & $\mathrm{C}$ & 0.619 & 0.187 & & 3.310 & 0.001 \\
\hline 1 & EI & 0.763 & 0.049 & 0.695 & 15.57 & 0.000 \\
\hline
\end{tabular}

a. Dependent Variable: Performance of MTNOs.

Key: EI- Employees' Involvement.

Data obtained for employees' involvement (Employees' autonomy, quality circles and employees' suggestion schemes) was regressed against the data for the dependent variable and multiple regression outcome put in Table XI:

TABLE XI: EI MEASURES AND PERFORMANCE

\begin{tabular}{|c|c|c|c|c|c|}
\hline \multirow[b]{2}{*}{ M } & \multicolumn{2}{|c|}{$\mathrm{UC}$} & \multicolumn{2}{|c|}{$\mathrm{SC}$} & \multirow[b]{2}{*}{ Sig } \\
\hline & B & Std. Error & Beta & $\mathrm{T}$ & \\
\hline $\mathrm{C}$ & 0.617 & 0.182 & & 3.390 & 0.001 \\
\hline EA & 0.189 & 0.049 & 0.182 & 3.857 & 0.000 \\
\hline QC & 0.325 & 0.066 & 0.317 & 4.924 & 0.000 \\
\hline ESS & 0.348 & 0.061 & 0.335 & 5.705 & 0.000 \\
\hline
\end{tabular}

a. Dependent Variable: Organizations' Performance.

Key: M - Model, EI - Employees' Involvement, EA - Employees Autonomy, QC - Quality Circles, ESS - Employees' Suggestion Schemes.

As shown on Table XI, employees' autonomy, quality circles and employees' suggestion schemes contributed positively and significantly to performance model $(\mathrm{T}=3.390$, $P<0.05)$ : All sub independent variables of employees' involvement had positive and significant contribution toward performance as follows: Employees' suggestion schemes ( $\mathrm{T}$ $=5.705, \mathrm{P}=0.000)$; quality circles $(\mathrm{T}=4.924, \mathrm{P}=0.000$; and employees' autonomy $\mathrm{T}=3.857, \mathrm{P}=0.000$ ). The standardized and unstandardized coefficients show that all sub independent variables of employees' involvement had positive effect on the dependent variable: employees' autonomy $(\beta=0.182$ and $\mathrm{P}$-value $=0.000)$; quality circles $(\beta$ $=0.317$, P-value $=0.000)$ and employees' suggestion schemes $(\beta=0.335, P=0.000)$. 
A regression equation usable to predict variation in the dependent variable for a unit change in either employees' autonomy, quality circles and employees' suggestion schemes can be written as:

$$
\mathrm{OP}=0.617+0.189(\mathrm{EA})+0.325(\mathrm{QC})+0.348(\mathrm{ESS})+\varepsilon
$$

Where:

$\mathrm{OP}=$ Performance of MTNOs;

$0.617=$ the $\mathrm{Y}$ - intercept constant;

$0.189, .325$, and 0.348 represents probable increase in organizations' performance of MTNOs caused by raising employees' autonomy, quality circles and employees' suggestion schemes by one unit, respectively;

$\mathrm{EA}=$ Employees' Autonomy;

$\mathrm{QC}=$ quality circles;

ESS = employees' suggestion schemes;

$\varepsilon=$ Error Term.

\section{Summary of Study Findings}

KMO test on the data of employees' involvement gave a value of 0.669 which was higher than the threshold minimum of 0.5 results and Bartlett's test was significant at $\mathrm{P}=0.000$. The connections between employees' autonomy, quality circles and employees' suggestion schemes and performance as per as per correlation analysis results were $(\mathrm{r}=0.362, \mathrm{P}<$ $0.05),(\mathrm{r}=0.198, \mathrm{P}<0.05)$ and $(\mathrm{r}=0.466, \mathrm{P}<0.05$, respectively. Simple regression analysis of the dependent variable and employees' involvement gave $\mathrm{R}=.695 ; \mathrm{R}^{2}$ $=.483$ and adjusted $\mathrm{R}^{2}=0.481$. ANOVA model for the simple regression analysis was significant at $\mathrm{F}=50.114(1,256) \mathrm{P}<$ .05 . Null hypothesis was tested and rejected at $\beta=0.695$ and $\mathrm{P}=0.000$. Multiple regression analysis involving employees' autonomy, quality circles and employees' suggestion schemes and the dependent variable revealed that all the three sub-variables of employees' involvement had a positive contribution to the dependent variable of the study.

\section{CONCLUSION}

The researcher concluded that there was a positive and significant correlation between independent variables and the dependent variable where $P<.05$. Simple regression analysis revealed a positive effect of employees' involvement on performance of MTNOs where the independent variable contributed to $48.3 \%$ of variation in dependent variable. Each measure of employees' involvement affected performance as follows: employees' autonomy $(\beta=0.182$ and $\mathrm{P}$-value $=$ $0.000)$; quality circles $(\beta=0.317, \mathrm{P}$-value $=0.000)$ and employees' suggestion schemes $(\beta=0.335, \mathrm{P}=0.000)$.

\section{A. Recommendations}

The researcher approved introduction and nurturing of employees' involvement practices in companies such as employees' autonomy, quality circles and employees' suggestion schemes throughout the organization to improve performance.

\section{B. Recommendations for Further Research}

Study design was cross-sectional where primary data was collected once. The researcher therefore recommends a similar study using different variables but using longitudinal research design. The scholar also suggests a similar study but focusing on different industries.

\section{REFERENCES}

[1] F. F. Oyebamiji, Influence of Employees Participation in Decision Making on Organization Performance:A Study of Ladoke Akintola University of Technology Teaching Hospital, Ogbomoso, Oyo State, Nigeria, International Journal of Innovative Social Sciences \& Humanities Research, 6(3), pp. 8-17, 2018.

[2] G. O.Udu, and C. A. Aturu-Aghedo, Effects of Participative Decision Making on the Performance of Federal Airports Authority of Nigeria (Faan), Lagos, International Journal of Human Resource Management and Research (IJHRMR), 6(4), pp. 2249-6874, 2016.

[3] L. K. Owalabi, and, A. S. Abdul-Hameed, Employee Involvement in Decision Making and Firms Performance in the Manufacturing Sector in Nigeria, Serbian Journal of Management, 6(1), pp. 1-15, 2011.

[4] F. Gino, How to Make Employees Feel Like They Own Their Work. Harvard Business Review, December 7, 2015.

[5] W. Rureri, An assessment on the role of employee involvement practice on performance of steel manufacturing companies in Kenya, Strategic Journal of Business \& Change Management, 4(3), pp. 273-282, 2017.

[6] J. W. Chesoli, Employee involvement in Decision Making on Performance of SME's in Kitale, TransNzoia County, Kenya, IJRDOJournal of Business Management, 4(2), pp. 65-71, 2018.

[7] Y. Ueda, Effect of job involvement on performance; evaluation of Organizational Citizenship Behaviour. International Journal of Business and Society, 13 (1), pp. 77-89, 2012.

[8] O. L. Kuye, and A. A. Sulaimon, Employee involvement in decision making and firms' performance in the manufacturing sector in Nigeria, Serbian Journal of Management, 6(1), pp. 1-15, 2011.

[9] J. A. Odero, and M. E. Makori, Employee involvement and employee performance: case of part time lecturers in public universities in Kenya International Journal of Management and Commerce Innovations, 5(2), pp. 1169-1178, 2018.

[10] D. Adom, E. K. Hussein, and J. A. Agyem, Theoretical and Conceptual Framework: Mandatory Ingredients of a Quality Research; International Journal Of Scientific Research, 7 (1), pp. 438-441, 2018

[11] D. Tipurić, (2018). Ownership culture ; Case study of Dalekovod. International journal of management cases. 10(2), pp. 12-21.

[12] V. O. Nwoko, and G. A Emerole, Effect of Employees Participation in Decision Making on Organizational Performance: A Study of National Root Crops Research Institutes Umudike, International Journal of Economics, Business and Management Research, 1(5), pp. 27-46, 2017.

[13] M. C. Edson, P. B. Henning, and S. Sankaran, A Guide to Systems Research: Philosophy, Processes and Practice. New York: Springer, 2016, pp. 184-189.

[14] C. R. Kothari, Research Methodology: Methods and Techniques (2nd revised ed.). New Dheli: New Age International (P) Ltd, 2010, pp. 223 238.

[15] R. V. Krejcie, and D. W. Morgan, Determining Sample Size for Research Activities, Educational and Psychological Measurement, 30, pp. 607-610, 1970.

[16] P. V. Sukhatme, B. V. Sukhatme, S. Sukhatme, \& C. Asok, Sampling Theory of Surveys with Applications. Ames, Iowa: Iowa State University Press, 1984, ch. 3, pp. 345-387.

[17] H. F. Kaiser, An index of factorial simplicity. Psychometrika, 39, pp. 31-36, 1974.

[18] C. A. Cerny, and H. F. Kaiser, A study of a measure of sampling adequacy for factor-analytic correlation matrices. Multivariate Behavioral Research, 12(1), pp. 43-47, 1977. 